\title{
THE SUPERFICIAL PALMAR ARCH: A MORPHOLOGICAL STUDY
}

\section{Ankita Saha ${ }^{1}$, Nidhi Lal ${ }^{*}$, Sharmila Pal ${ }^{3}$.}

${ }^{1}$ Post-graduate Student, Department of Anatomy, Medical College and Hospital, Kolkata, West Bengal, India.

${ }^{* 2}$ Assistant Professor, Department of Anatomy, Medical College and Hospital, Kolkata, West Bengal, India.

${ }^{3}$ Professor \& HOD, Department of Anatomy, Medical College and Hospital, Kolkata, West Bengal, India.

\section{ABSTRACT}

Background: The functional importance of hand is revealed by its rich vascularity contributed by superficial and deep palmar arches (SPA and DPA). The efficiency of collateral circulation in hand by SPA and DPA is essential in certain peripheral vascular diseases like Raynaud's disease and in harvesting radial artery for coronary artery bypass graft (CABG). Knowledge of variations in the arterial supply of hand is important while performing microsurgical procedures like arterial repair, vascular graft and flap application.

Objective: To study the morphology of the Superficial Palmar Arch and variation in its formation.

Materials and methods: We have dissected 30 cadaveric hands at Department of Anatomy of Medical College and Hospital, Kolkata.

Result and conclusion: Out of 30 specimens, variations were observed in 14 specimens. Out of 14 specimens in 11 specimens SPA was formed alone by Ulnar Artery, in two specimens SPA was incomplete formed by superficial palmar branches of Ulnar and Radial Artery, in one specimen there was presence of Persistent Median Artery with incomplete SPA. All the variations found were present unilaterally. In rest 16 specimens SPA was complete classical radio-ulnar type.

KEY WORDS: Superficial palmar arch (SPA), Ulnar artery (UA), Radial artery (RA), Persistent Median artery (PMA).

Address for Correspondence: Dr. Nidhi Lal, Assistant Professor, Department of Anatomy, Medical College and Hospital, Kolkata, West Bengal, India. E-Mail: nidhi25_lal@rediffmail.com

Access this Article online

Quick Response code

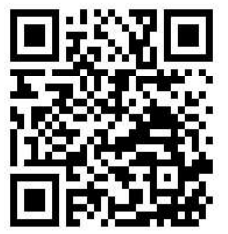

DOI: $10.16965 /$ ijar.2019.256

Journal Information

International Journal of Anatomy and Research

ICV for 2016
$\mathbf{9 0 . 3 0}$ $\begin{gathered}\text { ISSN (E) 2321-4287 I ISSN (P) 2321-8967 } \\ \text { https://www.ijmhr.org/ijar.htm } \\ \text { DOI-Prefix: https://dx.doi.org/10.16965/ijar }\end{gathered}$

Article Information

Received: 20 Jun 2019

Peer Review: 20 Jun 2019

Revised: None
Accepted: 05 Aug 2019

Published (O): 05 Sep 2019

Published (P): 05 Sep 2019

\section{INTRODUCTION}

Arterial dominance of the hand is provided by an intricate network of collateral flow referred as the superficial (SPA) and deep (DPA) palmar arches.

SPA is principally formed by ulnar artery (UA), completed on lateral side by the superficial branch of radial artery (RA) or Arteria Princeps Pollicis (APP) or Arteria Radialis Indices (ARI) or median artery (MA) (Standing S et al) [1].
The SPA gives four palmar digital arteries. The most medial palmar digital artery supply the medial margin of little finger so that it is termed as proper palmar digital artery. The remaining three palmar digital arteries are known as common digital branches. Each one divides into two proper digital branches to the adjacent sides of little and ring fingers, ring and middle fingers, middle and ulnar side of index fingers by passing through interdigital clefts. The 
radial side of index finger and adjacent sides of the thumb supplied by branches of radial artery. SPA lies between Palmar aponeurosis and long flexor tendons of hand (Standring $S$ et al) [1]. The anastomoses between the radial and ulnar arteries in SPA and DPA play very important role through collateral circulation in diseases and traumatic conditions of palm. The knowledge of anatomical variations of palmar arches is essential for safe surgical procedures of the hand like arterial repairs, vascular graft and free or peddled flap application.

SPA has been classified as Complete or Incomplete arch by Gellman et al [2], Coleman and Anson [3].

Adachi [4] classified SPA as ulnar type, radioulnar type, median ulnar type.

Median artery (MA) is normally a transitory vessel, which develops from axial artery of the upper extremity during early embryonic life. It maintains the SPA while ulnar and radial arteries are developing. After the 8th week of intrauterine life, the ulnar and radial arteries develop and the median artery usually undergoes retrogression to become a small vessel accompanying the median nerve ( $\mathrm{MN}$ ) in the carpal tunnel (Singer E et al) [5].

According to Jones NF [6], MA usually involutes when UA, RA develops and do not persist in post foetal life. The origin of median artery in adults have been previously described as arising from ulnar, interosseous, radial or brachial arteries (Henneberg)[7].

According to Rodriguez - Niedenfuhr 1999 [8]: in adults MA may persists in two forms- Palmar and Antebrachial.

\section{The palmar type shows two variants:}

Long type- which ends in the SPA through small arterioles.

Digital type- MA doesn't contribute in formation of SPA but supply the hand by giving common \& proper digital branches.

The antebrachial type is slender, short and terminates before reaching the wrist. Shows two variants:

Atrophic type - termination of MA in upper third of forearm.

Carpal type - termination of MA in the distal third of forearm.

The Palmar type is intimately related to the median nerve, reaches the wrist and enters the palm by passing beneath the flexor retinaculum and may take part in formation of SPA [9].

The MA due to its close proximity to Median nerve $(\mathrm{MN})$ can be involved in several clinical disorders like Carpal Tunnel Syndrome (CTS) [10, 11, 12]; Anterior Interosseous syndrome (AIS) [13]; Pronator syndrome (PTS) [6]. According to D' Costa et al [14] Palmar type of MA has high incidence of mentioned syndromes than antebrachial type.

Aim and objectives: The present work was proposed to study the morphology of the Superficial Palmar Arch and variation in its formation.

\section{MATERIALS AND METHODS}

A total of 15 cadavers ( 30 adult cadaveric hands) embalmed with formaldehyde comprising 12 males \& 3 female cadavers. All specimens were dissected during routine curriculum dissection classes in the Anatomy department of Medical College and Hospital Kolkata, India. Any external trauma or pathology was absent among the chosen specimens.

Palmar arches in them were dissected following classic incisions and dissection procedures of Cunningham's manual [15] and observations were then tabulated according to Adachi [4] and Coleman and Anson [3] classification of SPA.

Coleman and Anson [3] studied the variations in vascular supply of hand \& classified SPA into Complete and Incomplete groups.

Group I: Complete SPAs into 5 categories, namely Type A, Type B, Type C, Type D, Type E.

Type A: The classical radio ulnar arch is formed by superficial palmar branch of RA \& UA.

Type B: This arch is formed entirely by UA.

Type C: Mediano ulnar arch is composed of UA and an enlarged MA.

Type D: Radio-mediano-ulnar arch in which three vessels enter in to the formation of arch.

Type E: It consists of a well formed arch initiated by ulnar artery and completed by a large sized vessel derived from deep arch.

Group II: Incomplete arch: When the contributing arteries to the superficial arch do not 
anastomose or when the ulnar artery fails to reach the thumb and index finger, the arch is incomplete.

Incomplete SPA subclassified into 4 categories, namely Type A, Type B, Type C, Type D.

Type A - has no anastomosis between superficial branches of RA and UA

Type B - SPA solely formed by UA.

Type C - SPA formed by ulnar and median arteries without anastomosis.

Type D- SPA varieties contributed by ulnar, median and radial arteries without any anastomosis between them.

SPA has also been classified by Adachi [4] as Ulnar, Radio - Ulnar, Mediano- Ulnar types depending on the vessels contributing to SPA.

\section{RESULTS}

Out of 30 specimens, variations were observed in 14 specimens present unilaterally. Out of 14 specimens in 11 specimens SPA was formed alone by Ulnar Artery and it gave princeps pollicis and radialis indices arteries. Among other 3 specimens, in two specimens (one male and one female) SPA was incomplete formed by superficial palmar branches of Ulnar and Radial Artery, in one specimen (male) there was presence of Persistent Median Artery with incomplete arch. In rest 16 specimens SPA was complete formed by UA and completed on lateral side by the superficial branch of Raidal artery (RA) or Arteria Princeps Pollicis, (APP) or Arteria Radialis Indices (ARI) .These variations were observed during the routine dissection classes.

Most common variation encountered was SPA formed alone by UA (Fig. 1).The UA entered the palm superficial to flexor retinaculum. At the distal border, it gave a deep branch \& continued as SPA supplying palmar aspect of all the fingers. It gave a proper digital branch to medial side of little finger, three common digital branches to the medial four fingers by dividing into two digital branches. Then it further continued to 1st web space and gave one more common digital artery which supplied the radial side of index finger and ulnar side of the thumb. This digital artery thus divides into Arteria princeps pollicis (APP) and Arteria radialis indices (ARI). The superficial branch of radial artery was small and terminated by nourishing the thenar muscles. The communication between the RA and UA was by completion of deep palmar arch through deep branch of UA, which maintains the collateral circulation of hand.

Fig. 1: Right hand showing SPA formed by UA alone.

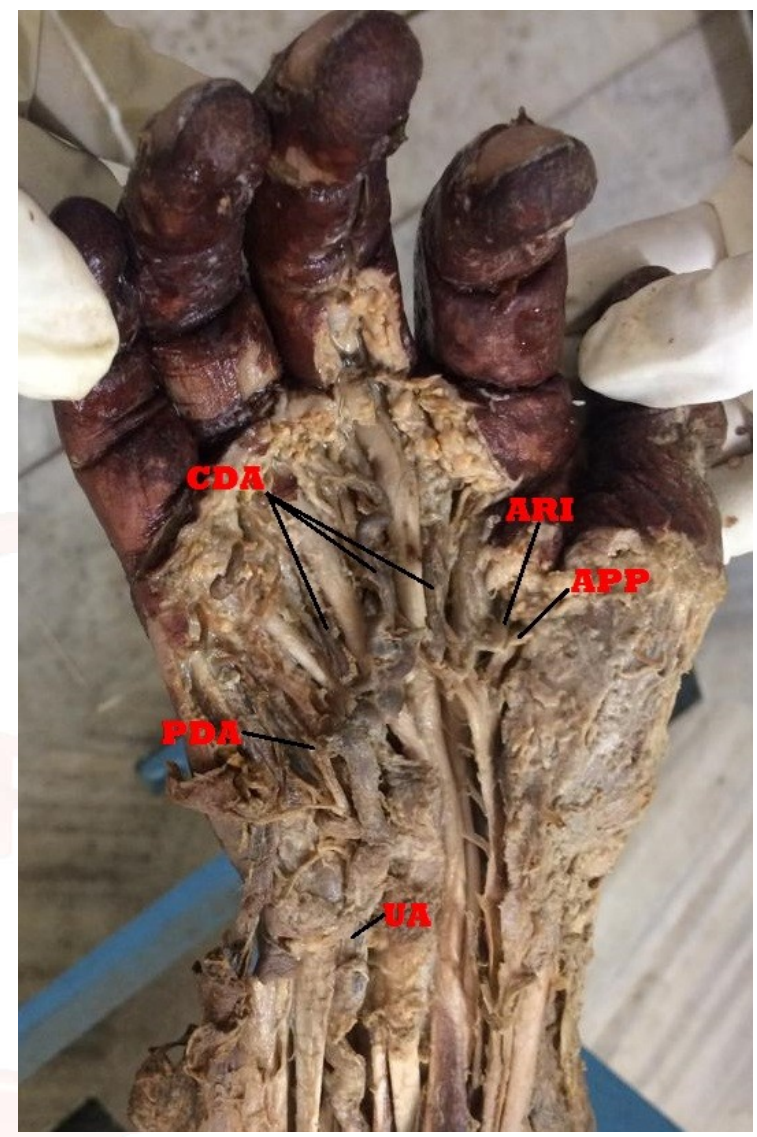

In one female cadaver and in one male cadaver we found incomplete SPA in the left hand formed by superficial branches of RA and UA (Fig.2).The superficial branches of UA and RA independently supplied the palm. UA entered the palm superficial to flexor retinaculum and its superficial branch gave off one proper digital branch to the ulnar side of little finger and three common digital branches to supply adjacent sides of little, ring, middle $\&$ index fingers.

The superficial branch of radial artery entered the hand superficial to thenar muscles and then gave off one proper digital branch to the radial side of the thumb and one common digital branch to supply the ulnar side of thumb (APP) and radial side of index finger (ARI).

On the right side in both cadavers SPA was complete as the traditional continuity between the superficial branches of UA and RA was maintained. 
Fig. 2: Left hand showing incomplete SPA formed by RA and UA.

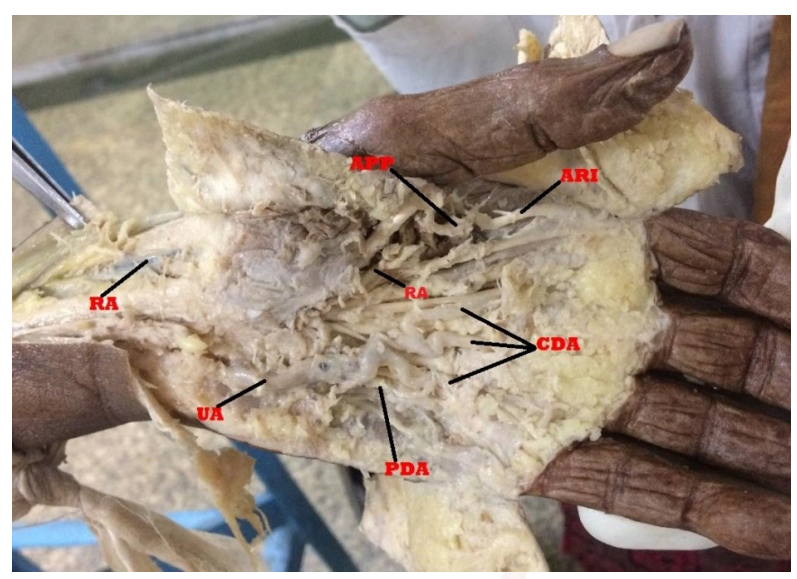

In one male cadaver we found in right hand Persistent Median artery not participating in formation of SPA with UA (Fig.3). UA entering the palm superficial to flexor retinaculum \& gave off one proper digital branch to the ulnar side of the little finger, two common digital branches to supply the adjacent sides of middle, ring and little fingers.

Median artery entered the palm in close relation with Median nerve (MN), deep to flexor retinaculum. MA gave two common digital branch for supplying adjacent sides of middle, index fingers and thumb.

In the same cadaver on left side SPA was formed by UA and completed on lateral side by Arteria Princeps pollicis.

Fig. 3: Right hand showing incomplete arch between UA and MA.

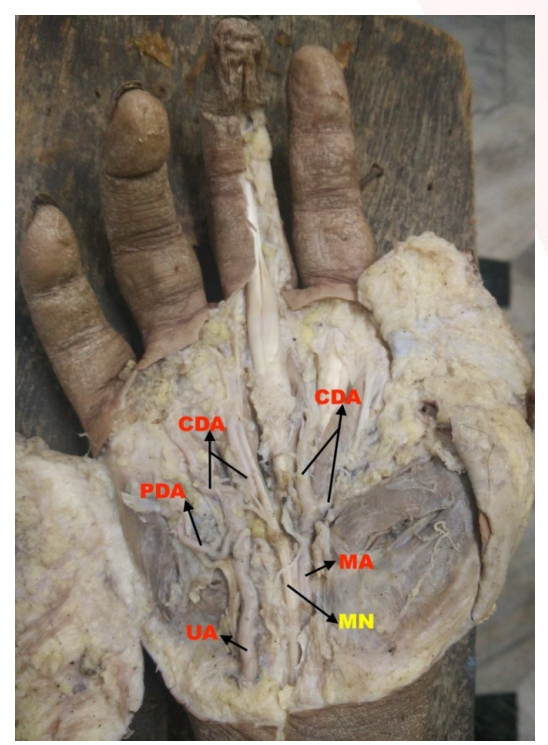

\section{DISCUSSION}

The vascular architecture of palm is a complex and challenging area. It has been the subject of many studies.
Gellman et al [2] proposed simple classification of SPA into complete and incomplete arch. In complete arch there will be anastomosis between vessels constituting it.

In Incomplete arch there will be an absence of a communication or anastomosis between vessels constituting it. Following this study we found total 16 complete SPA and 14 incomplete SPA.

In present study, in 11 hands SPA was found to be formed by UA alone, also giving rise to APP and ARI. This belonged to 'Type $B$ variety of complete arch' by Coleman and Anson's classification.

In 16 specimens we found classical radio-ulnar arch belonging to 'Type A variety of complete palmar arch'.

In 2 specimens we found RA \& UA independently supplying the palm belonging to 'Type A variety of incomplete palmar arch' of Coleman and Anson's classification.

In one specimen we observed in right hand of one middle aged male cadaver an incomplete arch belonging to the 'Type $C$ variety of Incomplete palmar arch'.

Table 1: Comparative study of SPA based on study of Coleman and Anson 1961.

\begin{tabular}{|c|c|c|c|c|c|c|}
\hline Sr No. & Features & $\begin{array}{c}\text { Coleman \& } \\
\text { Anson [3] }\end{array}$ & $\begin{array}{c}\text { S. Singh } \\
{[16]}\end{array}$ & $\begin{array}{c}\text { Al Turk et } \\
\text { al [17] }\end{array}$ & $\begin{array}{c}\text { Patnaik } \\
\text { et al [18] }\end{array}$ & $\begin{array}{c}\text { Present study } \\
\text { (2018-19) }\end{array}$ \\
\hline & Sample size & 650 & 100 & 50 & 50 & 30 \\
\hline \multirow{5}{*}{1} & Gp I & $78.50 \%$ & $92 \%$ & $84 \%$ & $78 \%$ & $90 \%$ \\
\cline { 2 - 7 } & Type A & $34.50 \%$ & $44 \%$ & $78 \%$ & $76 \%$ & $53.33 \%$ \\
\cline { 2 - 7 } & Type B & $37 \%$ & $46 \%$ & $4 \%$ & $2 \%$ & $36.66 \%$ \\
\cline { 2 - 7 } & Type C & $3.80 \%$ & $2 \%$ & $2 \%$ & & \\
\cline { 2 - 7 } & Type D & $1.20 \%$ & & & & \\
\cline { 2 - 7 } & Type E & $2 \%$ & & & & \\
\hline \multirow{5}{*}{2} & Gp. II & $21.50 \%$ & $8 \%$ & $16 \%$ & $16 \%$ & $10 \%$ \\
\cline { 2 - 7 } & Type A & $3.20 \%$ & $8 \%$ & $8 \%$ & $12 \%$ & $6.66 \%$ \\
\cline { 2 - 7 } & Type B & $13.40 \%$ & & $4 \%$ & - & - \\
\cline { 2 - 7 } & Type C & $3.80 \%$ & & $2 \%$ & $4 \%$ & $3.33 \%$ \\
\cline { 2 - 7 } & Type D & - & & $2 \%$ & - & - \\
\hline
\end{tabular}

In our study most commonly found pattern of SPA is complete Radio-UInar Type (53.33\% cases).

Based on the study of Adachi [4] we found 11 ulnar types, 18 Radio-ulnar types and 1 Mediano-ulnar type.

MA we found in right hand of one specimen belonged to Palmar Digital type of MA as reported by Rodriguez- Niedenfuhr et al [8].

Presence of mediano- ulnar arch has been reported by many authors. 
Coleman and Anson [3] reported incidence of PMA is 9.9\% \& Rodriguez-Niedenfuhr et al [8] reported $12 \%$.

Ikeda et al 1988 [19] conducted a study on 220 hands \& found mediano-ulnar type SPA in $0.9 \%$ subjects.

In 1992 Henneberg and George [7] reported a high incidence (27.1\%) of the MA Among South African cadavers.

Soubhagya R Nayak et al [20], conducted a study on 84 upper limbs of embalmed human cadavers \& found PMA in $15.4 \%$. Out of this $3.5 \%$ showed Incomplete SPA with PMA.

Ruengsakulrach et al [21] reported presence of PMA in $6 \%$ out of 50 cadaveric hands. One MA terminated at the wrist and one anastomosed with SPA. The 3rd MA terminated by giving off branches to index finger and thumb at the palmar side without anastomosing with UA or RA. Also found complete SPA in $66 \%$ \& incomplete SPA in $34 \%$ subjects.

This study correlated with ours as we have also found incomplete SPA with PMA which terminated by giving off branches to index and thumb as well as radial side of middle finger.

It is interesting to note that many authors have tried to explore the anatomy and morphology of superficial palmar arches and very few have reported similar results and percentages. This may be due to differences in races, sample size, geographical distribution.

Table 2: Comparative study of SPA based on the study of Adachi 1928.

\begin{tabular}{|c|c|c|c|c|c|}
\hline $\begin{array}{r}\text { Sr. } \\
\text { No. }\end{array}$ & SPA Types & Adachi [1] & Silvia [22] & Sheetal [23] & $\begin{array}{c}\text { Present study } \\
\text { (2018-19) }\end{array}$ \\
\hline 1 & Ulnar Type & $59 \%$ & $23.34 \%$ & $66 \%$ & $36.67 \%$ \\
\hline 2 & Radio- ulnar & $32 \%$ & $63.33 \%$ & $30 \%$ & $60 \%$ \\
\hline 3 & Mediano-ulnar & $9 \%$ & $13.33 \%$ & $4 \%$ & $3.33 \%$ \\
\hline
\end{tabular}

\section{CONCLUSION}

The findings of our study suggest that majority of hands showed complete arch which implies that collateral circulation is present in majority of cases. This would result in least number of complications considering RA harvesting for coronary bypass.

When SPA is solely formed by UA, any injury to ulnar side of palm can affect the blood supply of entire superficial structures of palm and it may lead to ischaemia associated with restricted movement of fingers.

This study also highlights a palmar type of digital variety of MA. No SPA is formed but UA and MA individually supply the respected areas of hand (Type C).The knowledge of medianulnar pattern of SPA helps in accurate planning and better performance of surgical procedures in the palm. In considering RA for coronary artery bypass the least number of complications may be expected when the MA is the main blood supply to the 1 st web space. Association of MA with $\mathrm{MN}$ should be considered in the evaluation of all patients with Carpal Tunnel Syndrome, Pronator Teres Syndrome , Anterior Interosseous Syndrome.

We also found Type A variety of Incomplete SPA (no anastomosis between RA and UA) which posses vulnerability to digital ischemic changes after trauma or after any intervention related to the radial artery. This variation also assumes importance in obstruction of arteries at the level of wrist occurring in 'Hypothenar Hammer Syndrome' and in connective tissue diseases.

\section{ABBREVIATION}

SPA- Superficial palmar arch

DPA- Deep Palmar arch

MA- Median Artery

PMA- Persistent Median Artery

UA- Ulnar Artery

RA- Radial Artery

APP- Arteria Princeps Pollicis

ARI- Arteria Radialis Indices

PDA- Proper Digital Artery

CDA-Common Digital Artery

\section{Conflicts of Interests: None}

\section{REFERENCES}

[1]. Standring Susan. Gray's anatomy : the anatomical basis of clinical practice (41 st ed.) Elsevier 2016; p.889-890.

[2]. Gellman H, Botte MJ, Shankwiler j, Gelberman RH. Arterial patterns of the deep and superficial palmar arches. ClinOrthopRelat Res 2001;383E:41-46.

[3]. Coleman SS, Anson BJ. Arterial patterns in the hand based upon a study of 650 specimens. SurgGynecolObstet 1961;113:409-24. 
[4]. Adachi B. Das Arteriensystem der Japaner; Kyoto, Maruzen. 1928; vol.1 ,pp. 285-356.

[5]. Singer E.Embryological patterns persisting in the arteries of the arm.Anatomical record.1933;55:40613.

[6]. Jones NF, Ming NL. Persistent median artery as a cause of pronator syndrome. J Hand Surg Am 1988;13:728-32.

[7]. Henneberg M, George BJ. High incidence of the median artery of the forearm in a sample of recent southern African cadavers. J Anat 1992;180:185-8.

[8]. Rodriguez-Niedenführ M, Sanudo J.R, Vázquez T, Nearn L, LoganB, Parkinl; Median artery revisited. J. Anat. (1999) 195, pp. 57-63.

[9]. Claassen H, Schmitt O, Wree A. Large patent median arteries and their relation to the superficial palmar arch with respect to history, size consideration and clinical consequences, SurgRadiol Anat. 2008;30:57-63.

[10]. BalakrishnanC1, Smith MF, Puri P. Acute carpal tunnel syndrome from thrombosed persistent median artery.JEmerg Med. 1999 May-Jun;17(3):437-9.

[11]. Gassner EM, Schocke M, Peer S, Schwabegger A, Jaschke W, BodnerG.Persistent median artery in the carpal tunnel: Color Doppler ultrasonographic findings. J Ultrasound Med 2002;21:455-61.

[12]. Natsis K., Jordache G., Gigis I., Kyriazidou,A., Lazaridis N., Nourrsions G., Paraskevas G. Persistent median artery in the carpal tunnel: anatomy, embryology, clinical significance and review of the literature. Folia Morphol. (2009) vol 68: no 4,193200.

[13]. Proudman T. W., Menz P. J. An anomaly of the median artery associated with the anterior interosseous nerve syndrome. J. Hand Surg. Br. (1992) vol17: 507-509.

[14]. D'Costa S., Narayana K., Narayan,P., Nayak S. R., Madhan S. J. Occurrence of and fate of palmar type of median artery. ANZ J. Surg. (2006) Vol 76: 484487.

[15]. Romanes G.J. Cunningham's Manual of Practical Anatomy, Upper \& Lower Limbs, 15th Edition, Oxford Medical Publications 2010; p77-7.
[16]. Singh S, Lazarus L, De Gama B.Z , Satyapal K.S. An anatomical investigation of the superficial and deep palmar arches. Folia Morphol., 2017, Vol. 76, No. 2 ,pp. 219-225.

[17]. Al-Turk M, Metcalf WK. A study of the superficial palmar arteries using the doppler ultrasonic flowmeter. J Anat 1984;138:27-32.

[18]. Patnaik VVG, Kalsey G, Singla RK. Palmar Arterial Arches- A Morphological Study. J Anat Soc India 2002;51(2):187-193.

[19]. Ikeda A, Ugawa A, Kazihara Y, Hamada N. Arterial patterns in the hand based on a three-dimensional analysis of 220 cadaver hands. J Hand Surg. 1988;13:501-509.

[20]. Nayak S.R, Krishnamurthy A, Kumar S.J, Prabhu L, Kumar B, D'Costa S, Ranade A.V; Palmar Type of Median Artery as a Source of Superficial Palmar Arch: A Cadaveric Study with Its Clinical Significance,American Association for Hand Surgery (2010) 5:31-36.

[21]. Ruengsakulrach P, Eizenberg N, Fahrer C, Fahrer M, Buxton BF; Surgical implications of variations in hand collateral circulation: anatomy revisited,JThoracCardiovasc Surg. 2001 Oct;122(4):682-6.

[22]. Sílvia Regina Arruda de Moraes, TâmaraNunes de Araújo, AlexandreRoque da Silva, Amanda Rodrigues de Paula, Juliana Larocerie Salgado. Morphologic variations of the superficial palmar arc. ActaCirurgicaBrasileira São Paulo. 2003;18(3).

[23]. Joshi SB,VatsalaswamyP, BaheteeB.H,Variation in Formation of Superficial Palmar Arches with Clinical Implications. Journal of Clinical and Diagnostic Research. 2014 Apr, Vol-8(4): AC06-AC09.

[24]. Loukas M, Holdman D, Holdman S. Anatomical variations of the superficial and deep palmar arches. Folia Morphol (Warsz) 2005;64:78-83.

How to cite this article:

Ankita Saha, Nidhi Lal, Sharmila Pal. THE SUPERFICIAL PALMAR ARCH: A MORPHOLOGICAL STUDY. Int J Anat Res 2019;7(3.3):6918-6923. DOI: 10.16965/ijar.2019.256 